\title{
INTEGRATING AND APPLYING MODELS OF COMFORT
}

\author{
Neil Mansfield, Department of Engineering, Nottingham Trent University, UK \\ Peter Vink, Faculty of Industrial Design Engineering, Landbergstraat 15, 2628 CE Delft, TU-Delft, \\ NETHERLANDS \\ Susanne Frohriep, Group Advanced Engineering, Dept. C-RD8-DE9, GRAMMER AG, GERMANY \\ Alessandro Naddeo, Dept. of Industrial Engineering, University of Salerno, ITALY
}

\begin{abstract}
This paper gives an overview of the relevance of the comfort concept, its definitions, boundary conditions and stakeholders. Current comfort theories are presented and reflected on, both in their applicability and testing methodology. Questionnaires commonly used to study comfort and discomfort are also reviewed. An example of a comfort lab is introduced in its functionality and tools, which can be useful as a benchmark for others studying comfort. The text concludes with an overview of the papers collected in this special issue of Applied Ergonomics.
\end{abstract}

\section{Keywords}

Product Design, Comfort Modelling, Discomfort, Review

\section{Comfort is in our daily lives}

When users interact with products they often rate their experience. When they consider buying a bed, a chair or a car, taking the train, holding a hand tool or flying across the ocean, comfort comes into play. Therefore, designers and manufacturers of products such as seats, cars, beds, hand tools, and production lines strive for optimal comfort or reduction of discomfort. If we look at some trends like "attention to health", "ageing workforce (and population)", "environmental awareness and sustainability" and "attention to well-being", (dis)comfort is an important consideration (Vink \& Hallbeck, 2012). Comfort and discomfort are part of our daily lives.

\section{Only the user decides whether it is comfortable}

The difficulty in studying comfort is that a product in itself can never be comfortable (Vink, 2005). It only becomes comfortable (or not) in its use. Despite an ongoing debate in literature on the meaning of comfort (Looze et al., 2003), it is generally accepted that comfort is a construct of a subjectively defined personal nature. The user decides whether or not a product is comfortable, or leads to discomfort, by using the product. Some have defined loose 'comfort' boundaries as an experience where pain receptors are not active (e.g. Mansfield et al., 2014) but even this is a difficult working boundary in some situations such as healthcare where comfort and pain can occur simultaneously. This makes designing a comfortable product difficult. On the other hand it is not impossible to design comfortable products. Efforts are being made to understand the genesis of the holistic comfort impression and to define the different aspects of comfort and corresponding test methodology for using human beings as measurement tools (Frohriep, 2009). One aspect is that the comfort experience cannot be better than its weakest aspect. On the other hand, several studies show that paying attention to a better product or service lead to more comfort, or less discomfort (Vink, 2005). 
Therefore, there is room for knowledge development supporting the design of more comfortable experiences and reducing discomfort.

\section{Challenge for companies}

The main challenge for companies that spend money and time for launching more appealing products on the market is to understand which mental/physical/physiological/ environmental mechanisms act in creating a (dis)comfort perception. Thus, in product design, designers and engineers, supported by Psychologists, Physiologists, Ergonomists, posture experts etc., try to work towards defining a comfort-driven step to take into account the improvement of comfort (or the decrease of discomfort) as new, mandatory, functional requirements of a new product (Cappetti, 2016). Nevertheless, there are few methods and instruments, models or experience, to optimize products for comfort consistently. The tools and knowledge for the early stages in the design process are missing and much is done in a later phase of design by testing the product or service and comparing it with previous versions or other benchmarks (Vink, 2017). This comparison is needed as humans are not good in sensing absolute values, but better in sensing differences between two conditions (Vink, 2014). (Dis) comfort assessments have to be performed as an "evaluation" step in the design process with higher costs and few possibilities to make changes for improvement.

\section{Comfort in scientific literature}

In the scientific domain the word comfort is often mentioned. Vink \& Hallbeck (2012) report 104,794 double reviewed papers in 30 years (between 1980 and 2010) including the term discomfort or comfort. One would think that literature thus covers comfort measurement and methodology amply. Most of these studies refer to temperature related discomfort or patient comfort. Bazley et al. (2015) showed more recently that in the scientific literature between 2003 and 2013 more papers are focused on discomfort than on comfort. Also in this study, patient (dis)comfort was the most mentioned. Other studies mention visual comfort, musculoskeletal discomfort, thermal comfort and discomfort, vibration and comfort related to products. The latter concerned only $5 \%$ of the papers. So, arguably, the most important application of comfort research into product design is a low priority in the literature and leaves many comfort aspects open to study.

Papers on theories explain more about the concept of comfort. Helander and Zhang (1997) describe terms underlying the concept of comfort and discomfort and De Looze et al. (2003), Kuijt-Evers et al. (2004), Vink \& Hallbeck (2012) and Naddeo et al., (2014) created models to explain and describe (dis)comfort. Also, comfort and discomfort in relation to products has been reported (e.g. Mansfield et al., 2014; Sammonds et al., 2017; Hiemstra-van Mastrigt, 2016). Most of these studies concern sitting. Even models that attempt a multi-factorial approach including, for example, dynamics, static, fatigue and temporal factors (Ebe and Griffin, 1998; Mansfield, 2005) tend to use a 'black box' to describe the components building these factors rather than building from the fundamental biomechanics, physiology and neurology.

Therefore, $t$ the theoretical foundations for comfort research remain underdeveloped, but the number of papers touching comfort knowledge continues to expand. As an example Kolich (2018) studied papers between 1969 and 2017 on the search terms "comfort", "thermal comfort", "seat comfort", "interior comfort" AND "automotive", "car", "automobile", "vehicle" AND NOT "aerospace", "airplane", "aerial vehicle", "submarine, "railroad transportation" and found 95,000 papers. Of the 95,000 papers 2,000 papers (per year), were solely focused on automotive comfort. 
Based on the aforementioned research literature, challenges and need for future opportunities for comfort research this special issue presents 22 research papers that primarily focus on product comfort and comfort theory, tools and methodology.

\section{MULTI FACTORIAL CONCEPTUAL MODELS}

According to Ahmadpour et al., (2016) and Bouwens et al., (2018)comfort is a construct comprising many factors. A manufacturer may decide to produce a high-valueperception item at a price that is commercially competitive. Therefore the manufacturer needs to understand how the customer (end-user) will interact with the product and what values and priorities the customer has.. Inevitably manufacturers strive to present this product in the best possible light, taking care to ensure that the finished product presented to a customer is ideal. Kolich (2018) found that $20 \%$ of the buyers of a Lincoln car mention seat comfort as principle buying argument. In the airline industry Brauer (2004) states that passengers first select point-to-point transport, time and price, then select aspects like marketing (frequent flyer programmes), followed by comfort. Kuijt-Evers (2007) states that hand tool manufacturers recognize comfort as a major selling point, and are considered as an increasingly important role in product buying decisions.

Using a 'cake model' as a metaphor (Figure 1), the cosmetic coating, demonstrates how the design produces an outstanding first-impression that could be applied but might keep some elements of the design hidden. Within the cake are multiple layers comprising of multitude design priorities.

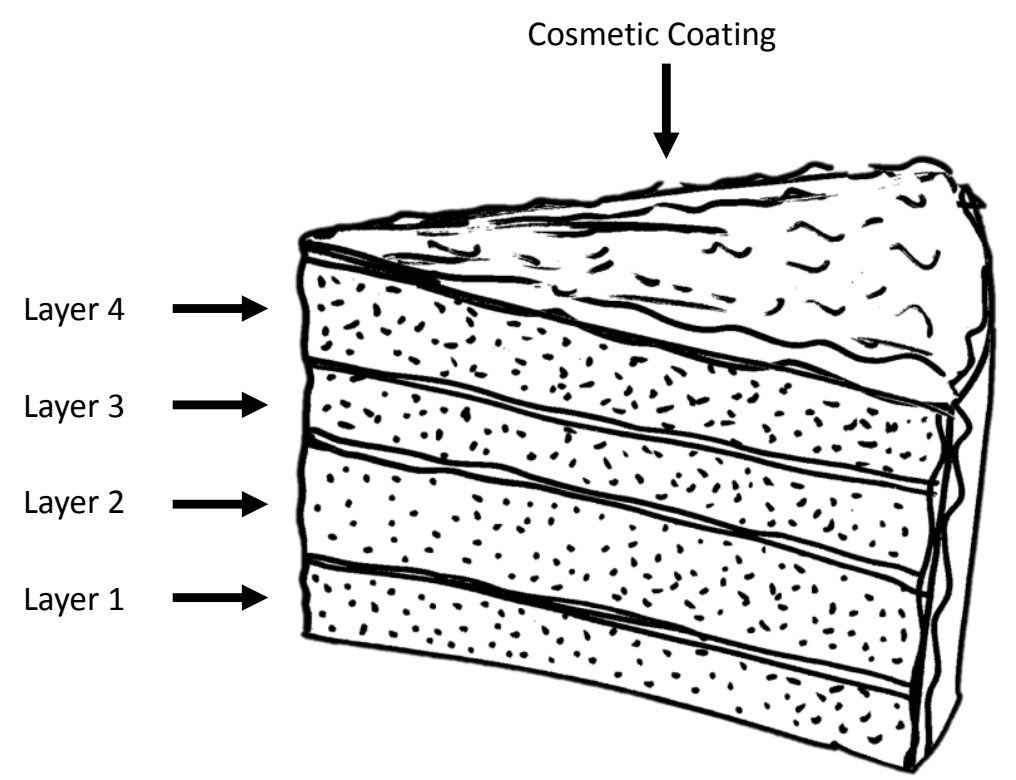

Figure 1: Conceptual 'cake' model, illustrating that multi-factorial layers must support subsequent layers in order for the cake to be defined acceptable. Layers vary depending on application but for a vehicle seat could include contouring, pressure distribution, thermal properties, and vibration isolation. The Cosmetic Coating including styling, texture, and colour, is an important final layer but supported by those beneath.

At a simple conceptual level, each of the layers may need optimisation in a different way; each layer requires different levels of prioritisation and investment depending on the application. For example, there could be differing requirements for thermal properties, lateral support, vibration damping, breathability, adjustability, etc. and dependent on the application, customer attributes and budget. For the entire experience 
to be acceptable, all elements must exceed minimum levels of performance in order to support subsequent layers; if any element fails, the entire customer experience risks collapse.

\section{DEVELOPMENT OF TWO-STAGE SUBJECTIVE DISCOMFORT QUESTIONNAIRE}

For studying the 'cosmetic coating' or other layers many methods are available. Several methods are frequently used to ask the subject to indicate their experienced comfort or discomfort through a survey or questionnaire, over time, during a task or series of tasks, with or without training. An interview may also be included in this study design method.

The local postural discomfort questionnaire is a method frequently used in comfort research. The method may be dated, but it is still a powerful technique in seat testing by Bronkhorst and Krause (2005), Smulders et al., (2016) and Groenesteijn (2015). In this method, subjects are first taught the Borg scale (0-10) (Borg, 1990). One method of training is for subjects to hold a $1 \mathrm{~kg}$ weight with a horizontally extended arm. At first, subjects feel very little discomfort. As time goes by, discomfort scores move up the scale towards extreme discomfort, until the point at which subjects can no longer hold the weight $(=10)$. The concept of comfort scoring can then be applied using a body map containing 12 regions, each of which is given a comfort score on the Borg Scale (Van der Grinten and Smitt, 1992). Usually a benchmark product is tested as part of a study to make a comparison possible. The advantage of this method is that it reveals the location of the areas to be improved, which provides input for redesign. The method is most powerful for long test trials (e.g. > 1 hour) as it takes time for discomfort to develop, especially in well-designed seats. The body map can also be used in a simpler manner. After spending time in the seat, subjects are asked to put red crosses on the body map where they feel discomfort, and green crosses where they feel comfort (Veen, 2016).

Another frequently used way of measuring discomfort is the CP-50 category partitioning scale described by Shen and Parsons (1997) and used, for instance, by Franz et al. (2012) and Mergl et al. (2005). In this method, subjects are asked to categorize their feeling after sitting for a certain amount of time by first assigning a descriptor category and then rating their discomfort within this category on a scale of $1-10$, amounting to a total possible range of 1 - 50. A score from 1-10 indicates very slight discomfort, 11-20 slight discomfort, 21-30 medium discomfort, 31-40 severe discomfort, and 41-50 very severe discomfort. Scores of 51 and 52 are for anything exceeding this. This type of questionnaire has the advantage of the subject's ability to zoom in on an area and rate it precisely.

Sometimes simpler methods are appropriate when it is not possible to extensively train volunteers. Franz et al. (2012) asked the subjects to rate discomfort levels for the back of the head, neck, and shoulder areas on a four-point scale.

There are a large number of comfort scales available to researchers (Kolich, 1999). They are frequently used in medical settings for establishing comfort in relation to temperature (Bazley et al., 2015), but these scales have also been applied to seat design. Groenesteijn et al. (2014), for instance, posed various comfort-related questions regarding specific parts of a journey. Participants were asked to rate these on a 10-point scale $(10=$ high, $1=$ low $)$. The passengers were asked about:

- their overall comfort experience;

- their seat comfort experience for the activity performed;

- their comfort experience of chair parts such as headrest, backrest and seat pan for the task/activity performed; 
- their comfort experience of seating space and of the table.

Another study by Groenesteijn et al. (2012) used a six-point scale for comfort ( 1 =very good, $6=$ very bad). These scales were all applied to specific questions. For instance: 'What are your expectations regarding the comfort of this chair?' (1=very good, $2=$ good, $3=$ rather good, $4=$ rather bad, $5=$ bad, $6=$ very bad). The most important thing is that the same questionnaire is used in both (or all) conditions. Ideally, the questionnaire is also completed while seated, as memory errors may occur once a subject has left their seat. It is also possible to ask questions whose answers provide explanations. For example, 'the chair feels soft: I agree--------I don't agree' (Veen, 2016), or 'the seat has a good lumbar support'.

Smulders (2017) covered test seats, as their appearance may influence perceptions of comfort. However, if the seat was a final design, the aesthetic could form the 'cosmetic coating' (figure 1) and provide important details to the final design. An additional disadvantage of covering the seats is that the texture and thermal conductivity could be changed. One solution is to ask the subjects to close their eyes, or, remove the sheet immediately prior to the subject sitting down (Hiemstra-van Mastrigt, 2016).

If the comfort of the tested seats is acceptable, longer sessions are often needed to distinguish differences. Veen (2016) could not elicit differences in BMW 7-series seats after 1 hour of driving, while Zenk (2008) could find a difference in BMW 7-series seats when adjusted according to the 'ideal position' as compared with the self-adjusted setting after 2 hours of driving.

In the cake model the cosmetic coating is shown, which is related to expectations and first impressions. Bazley (2015) showed that expectations influence the comfort experience in airplanes, control rooms, workplaces and healthcare waiting rooms. In a short term experiment, Kuijt-Evers (in Bronkhorst, 2001) showed that 49 experienced office workers evaluated one out of four office chairs negatively based on visual information. The four seats were exactly the same physically, and only differed in terms of colour. Three seats were light in colour and one was brown. The first impression was that the brown seat would be less comfortable, and the first seating experience after this visual impression resulted in lower comfort ratings. However, the brown chair was evaluated positively and equal to the other chairs after being used for more than an hour of office work. Bouwens et al. (2016) described the difference between the first impression and comfort after experiencing the product. In this study of aircraft seats, a collar (the 'embrace' sleep collar) was used as neck support rated low on comfort from a visual perspective before the physical experience of the collar or usability test. After the usability, 'embrace' sleep collar was rated one of the best neck pillows regarding comfort.

\section{OVERALL (DIS) COMFORT MODELS}

In the cake-model, both cosmetic coatings and hidden elements contribute to the overall comfort experience. The first impression, generally visual and tactile, may be misleading and unrepresentative of the overall comfort when used and experienced with additional senses, cultural considerations, expectations and over time. The literature shows that the product characteristics of individual elements cannot be simply summed, and that interactions and the breadth of users and use-cases must not be neglected.

In the past, the principles of ergonomics were defined as methods for creating products, environments and systems that that are fit for human use (Pheasant and Haslegrave, 2006). This includes studying the interfaces between people, the activities they perform, 
the products they use, and the environments in which they work, travel or play. As stated in Mokdad and Al-Ansari (2009), ergonomics principles allow us to develop guidelines for improving and redesigning both old and new products.

A wide range of research on physical comfort and discomfort in the workplace has been carried out. Most papers discuss the relationships between environmental factors that can affect perceived levels of comfort/discomfort, such as temperature, humidity, applied forces, and others (Galinsky et al., 2000). Several papers follow the assumption that a relationship exists between self-reported discomfort and musculoskeletal injuries, with these injuries affecting perceived comfort (Hamberg-van Reenen et al., 2008; A. Naddeo et al., 2009). Hamberg-van Reenen et al. (2008) followed 1800 workers that demonstrated the same posture during the work week and recorded discomfort. Peak discomfort was defined as a discomfort level of 2 using the above described LPD method at least at one moment during a day. Cumulative discomfort was defined as the sum of discomfort during the day. Reference workers were the ones reporting a rating of zero at each measurement. This group of 1800 workers was followed for 3 years and the back pain was recorded in this group. Peak discomfort appeared to be a predictor of low-back pain (relative risk (RR) 1.8), neck pain (RR 2.6) or shoulder pain (RR 1.9). Cumulative discomfort predicted neck pain or shoulder pain. So, whilst peak and cumulative discomfort is related to musculoskeletal pain underlying theories relating comfort to products and product design characteristics are rather underdeveloped.

The last 15 years have seen only five "comprehensive models" that considered every aspect of human perception and of human interaction with the environment: the Helander model Helander \& Zhang (1997), the Moes model (Moes, 2005), the VinkHallbeck model (Vink \& Hallbeck, 2012), the Naddeo-Cappetti-Oria model (Naddeo et al., 2015) the Vink model (2014) and the Bouwens model (Bouwens et al., 2018).

The new proposal for comfort perception model as shown in figure 2 (Naddeo et al., 2015) is the Naddeo-Cappetti (NC-model, 2014) model, starting from the Vink-Hallbeck model (Vink \& Hallbeck, 2012) and explains (dis)comfort perception

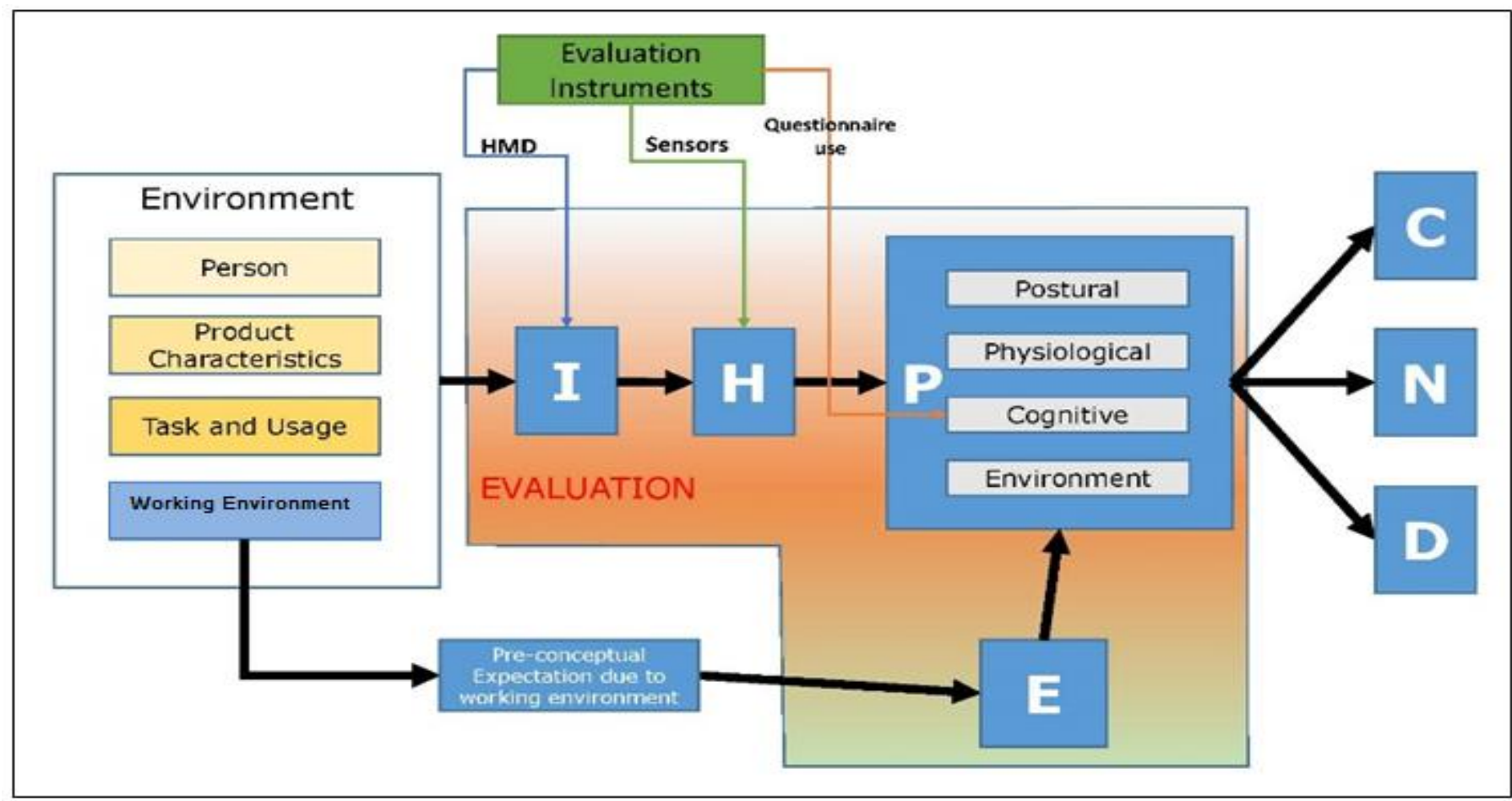


Figure 2: New proposal for comfort perception model according to Naddeo-Capetti-Orio (Naddeo et al., 2015)

In this model, the Environment is represented by the logic sum of five main aspects that contribute to HMI description and classification:

- Person (Pe): represents the whole body geometric and personal characteristics of human involved in tasks;

- Product (Pr): represents all geometric and non-geometric characteristics that describe the element that come in contact with the human body during task execution (shape, materials, colour, surfaces' treatment and so on...);

- Task/Usage (T\&U): represents all the task or the use that humans can do during HAI (Human-Artefact Interaction (Vink, 2014)) experience (kind of contact, timing, kind of interaction);

- Working environment (We): represents the set of parameters that characterizes the working environment, both under climate and under layout point of view (temperature, humidity, lighting, working seat, kind of workspace);

- Satisfaction/Gratification level and Emotions (G\&E): represents the set of information describing the state of mind and the emotional state that contribute to the satisfaction/dissatisfaction of worker (job position in organization chart, working shifts, gratification, salary and so on) and is widely related to the general environment.

In the NC-model, the Vink/Hallbeck model (2012) is integrated with a relation that directly connects the environment in which the comfort/discomfort is experienced with the expectation through the coding of several pre-conceptual aspects due to not only the same environment but also to the cultural/experience background of the worker. An aspect that cannot be underestimated, because it is always present when a comfort/discomfort evaluation is performed, is also integrated into this model: the perception modification due to experimental devices needed to evaluate comfort. These "devices" can modify most of contributes to the formation of the comfort/discomfort perception. For example, a HMD (Head mounted display) used for VR (Virtual Reality) application in HMI evaluation can modify the Postural Comfort Perception (Interaction I); the use of markers/sensors on the naked body to perform pressure/temperature/ movement data acquisition can change the Physiological Comfort Perception (Human Body effect $-\mathrm{H}$ ); the use of questionnaire can annoy the workers and directly modify his Cognitive Comfort perception (Perceived effects $-\mathrm{P}$ ).

This model shows the relevance of the sum of environmental conditions in predicting the comfort performance and the importance of the chosen instruments to investigate it. The cake-model can be perfectly integrated in the model and can be useful to prioritize the affecting elements in order to drive both the (dis)comfort analyses and the design/redesign of new product.

In Naddeo et al. (2014), the Comfort and Discomfort models have been translated in those conceptual equations;

$C_{i}=\operatorname{Mod}_{C} * P_{C}(h(P e, P r, T \& U, W e, G \& E))-E$
$D_{i}=\operatorname{Mod}_{D} * P_{D}(h(P e, P r, T \& U, W e, G \& E))+E$

In which:

- Mod $=$ Modifier of $\mathbf{P}$ (Perception) of the $\mathbf{h}=$ Human body effect due to: 
- $\boldsymbol{P e}=$ Personal characteristics

- $\boldsymbol{P r}=$ Product characteristics

- $\quad \boldsymbol{T} \& \boldsymbol{U}=$ Task and usage

- $\boldsymbol{W e}=$ Working environment (environment where activity is performed)

- $\boldsymbol{G \& E}=$ Gratification level and emotions

- $\boldsymbol{E}=$ Expectations

- $\mathbf{C i}$ is one of the four kinds of Comfort: Postural, Physiologic, Cognitive \& Psychologic, Environmental \& Organizational

- Di is one of the four kinds of Discomfort: Postural, Physiologic, Cognitive \& Psychologic, Environmental \& Organizational
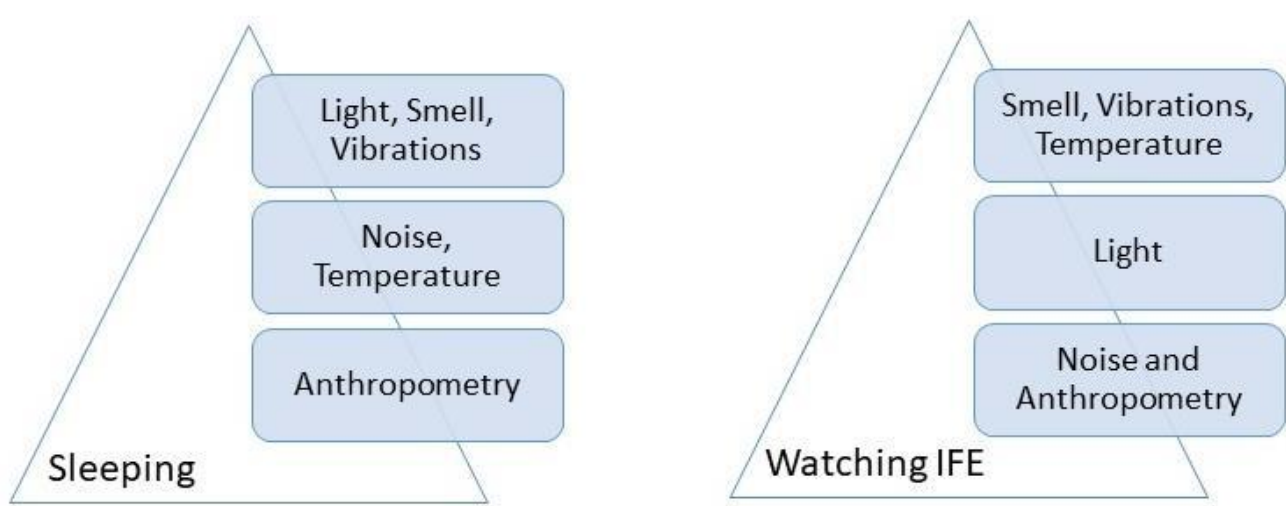

Fig. 3. The importance of different senses influencing comfort according to a study of Bouwens et al. (2018)

The Bouwens model (see fig. 3) describes the importance of the different senses for comfort. It is based on questionnaires completed by 167 respondents between 19 and 61 years old in the context of aircraft interiors. For different activities the importance was rated differently. In both sleeping and watching IFE anthropometry was the most important factor and vibrations the least important, while other factors like light, noise and smell differed per activity. For trains, cars, office seats and using hand tools the order could be different.

Taking a look at the (dis)comfort models described above all of them may be seen as a part of the general model expressed in the formula of Naddeo et al. (2017).

Nevertheless, most of these address a specific, context-related issue but contributes, in specific fields like seat-design or tools design, to design product in a comfort-driven way.

However, this formula is merely a theoretical description without direct application, as it requires that the function describing the relationship between a factor influencing (dis)comfort perception and the perception is defined. This is a challenge that scientists must face when implementing a model that allows performing a preventive analysis of (dis)comfort in the virtual design process. Within a comparable application context results can be useful for ranking, but objective scores are difficult to transfer between contexts.

The cake model is useful in describing the influence of $\operatorname{Pr}, T \& U, \operatorname{Mod}_{i}$ and $E$. The (dis)comfort perception model shows how it is not possible to focus the attention on the product and its use when dealing with perceived comfort: it is necessary to broaden the 
cake by involving and taking into account the Working/use environment and the own characteristics of the user (G\&E).

The cake coating (first impression) is one of the main factors affecting expectations that, as demonstrated in (Naddeo et al., 2016), plays a fundamental role both in comfort and in discomfort experience.

\section{HOW VIRTUAL PROTOTYPING CAN HELP TO IMPROVE THE COMFORT EXPERIENCE}

The use of both mathematical and engineering models in engineering design allows designers to speed up the design process and to improve and optimise their results from different perspectives. The use of models that describe the 'behaviour' of a product (artefact) in terms of a human-artefact interface (HAI) can help designers include HCD optimisation as a step in the design cycle. In products development this is called the 'virtual prototype' used in designing and operating in the digital world (Uhleman et al., 2017). The design cycle can be summarised by the following diagram in Fig.4:

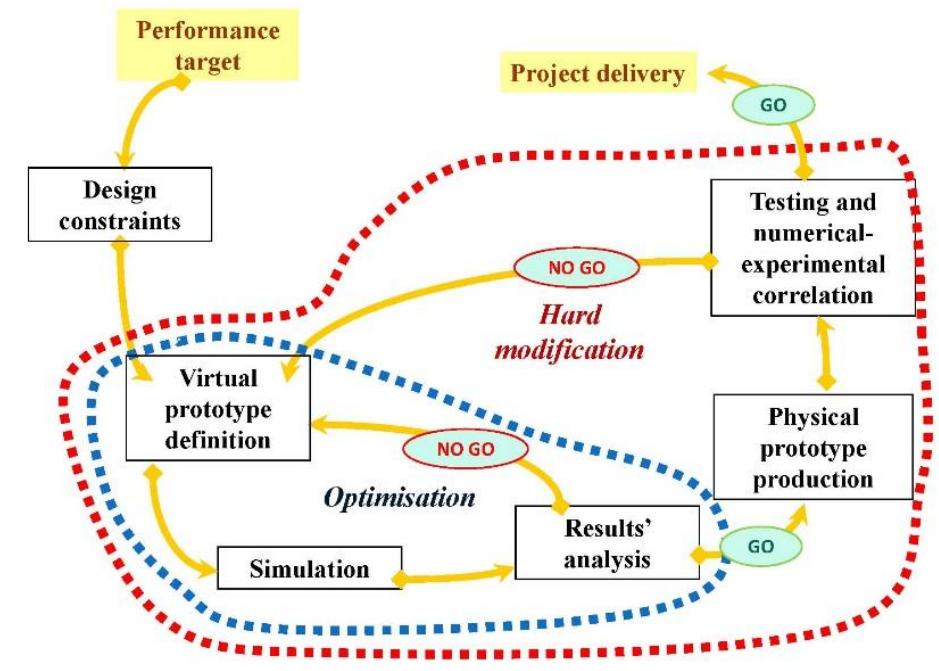

Figure 4: Product design and development diagram in digital era (Naddeo, 2017)

In this process, target setting generally begins with customer needs and the functional requirements of the final artefact. When introducing HCD to the artefact development plan, we require models that describe the HAI in the very early phase of the design. Contrarily, (dis)comfort performances can be discovered and evaluated only after the production of a physical prototype. Due to the subjectivity of comfort perception, it is difficult to objectivise this kind of performance via a model, and integrating these models into the artefact development plan is even more challenging. To achieve this requires the integration of the standard or non-standard design methods and the techniques for modelling (dis)comfort behaviour. Simply stated, there is a need to create a comfortdriven design method that can be applied to the early phase of the design process and that can help designers and engineers optimise the product by introducing comfortrelated issues in the target-setting phase. 


\section{EMPLOYING COMFORT MODELS}

From a manufacturer's standpoint, comfort is relevant because it ultimately sells products. Product development that rests upon scientific findings can enable companies to produce better products than their competitors. The target of product development is to engineer products that are rated positively by a high percentage of their users. Comfort models define the framework for a human-centered product development. Embracing human variability calls for modern, versatile, smart products for the global market.

In product manufacturing, the development starts in the fuzzy front end, where ideas are developed, trends are studied and first ideas are discussed within the company, suppliers and potential end-users (Hofmann, 2018). Then usually a virtual phase follows with design sketches and CAD, with the goal of achieving comfort for products in use. In the further steps towards an industrialized product, comfort testing is applied to ensure perceived quality for the respective product application. The cake model points to the fact that the first interaction with the product is visual, and subsequent interactions are physical, with changing parameters over time, and at some time there is a product experience phase (Hekkert \& Schifferstein, 2007). The presented "cake" could have more or less layers, depending on the requirements of different customers. For example, for commercial vehicle seats longer interaction time needs to be taken into consideration than for automotive seats. The Naddeo-Capetti model points to the fact that tasks and usage have a large effect on human-product interaction and that this is strongly influenced also by the respective environment and the culture of the user. Thus, employing comfort models in product development mandates researching products in use and basing product design on users and use cases.

\section{OPERATIONALIZING COMFORT FOR PRODUCT DEVELOPMENT: AN EXAMPLE}

For understanding users and use cases, understanding the nature of comfort is essential: experiencing comfort in user-product interaction is the result of internal human computing of sensory input into a holistic impression in a fluid process over interaction time. Human beings compute this holistic interaction rating with little conscious effort, and generally with low awareness for its components. When an aspect comes to the attention of the user and becomes prevalent within the overall impression, it will dominate the comfort rating. This can occur in either direction: The negative occurrence has been named "limiting comfort factor", such that the holistic comfort experience cannot be better than its weakest aspect. The positive occurrence can be referred to as the "wow-factor" of a product, exceeding the expectation of the user. Thus, experiencing comfort encompasses all human senses and can be defined as "an overall positive user interaction experience with a product". To operationalize this, targets and methods development for comfort and discomfort testing are necessary. In practical testing, it is useful to limit the (principally infinite) influencing factors, but without losing the system out of view. 


\section{ERGONOMICS AND INNOVATION LAB TARGETS AND FUNCTIONS OF THE EXAMPLE}

The field of ergonomics provides the compendium for analysing and rating the interaction between user and product. Its goal is to understand the system fully and optimize this interaction. In order to be able to do this, human beings in their variation are the foundation. Humans vary regarding perception in terms of mental processes, anthropometry, biomechanics, and physiology. The assessment of these characteristics is needed. Perception refers to the human senses, their information processing and rating of the sensory input. Anthropometry applies human dimensions in their global diversity. Biomechanics analyses human movement, body structures and their kinematics. Human physiology respects the equilibrium of the functioning body, for example in breathing, blood flow, temperature, and biochemical processes. All of these fields contain useful information to optimize comfort and form the basis for humancentred product optimization; the list could be modified to best match the application.

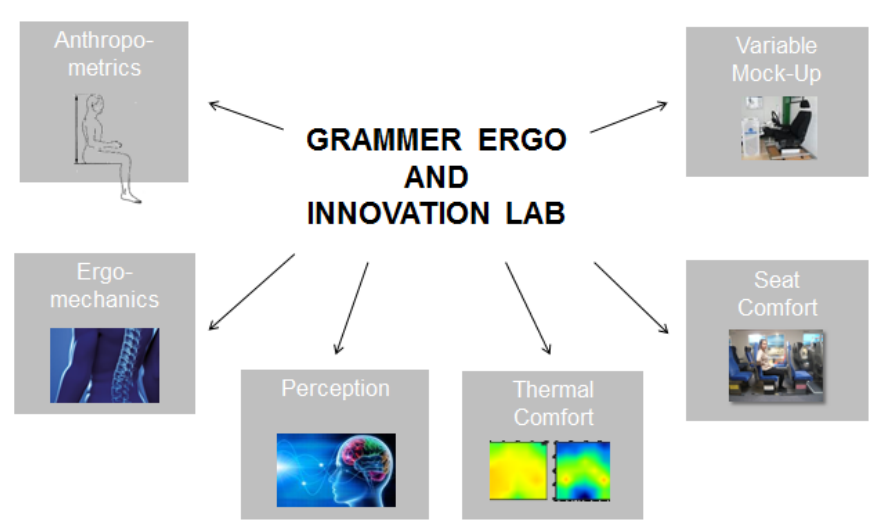


Figure. 6: An example of a lab in a company (Grammer AG) highlighting priority domains contributing to product design for comfort.

For the domain of anthropometrics, an internal test subject panel with assessed body measures and preferences is useful to provide information for the design and testing. User typology also falls into this domain, analysing human variation for specific applications. The ergomechanics $\AA$ domain (Frohriep, 2017) is concerned with ergonomics research and biomechanics. It incorporates current research on spine physiology for developing product details in its application. In the perception domain, the experience of operator systems and interactions are evaluated. Cognitive assessment and functional mapping of use cases are a valuable basis of operator workload and user experience. By measuring temperature and humidity in the human-seat interface in combination with subjective thermal comfort assessment, the effectiveness of active and passive climate systems can be verified. The approach aims to combine physical and cognitive elements of comfort. Flexible mock-ups are useful in providing environments for giving the user orientation as to elements such as steering wheel, pedal plane, roofline, and vehicle interior dimensions, in order to be able to test seats and components with test subjects. When a product or prototype is ready, vehicle fieldtesting is an important instrument with the respective defined test procedures for higher external validity.

\section{APPLYING THE PRINCIPLES OF COMFORT METHODOLOGY IN PRODUCT DEVELOPMENT}

This article started by stating that product comfort originates in use and that a product itself cannot by definition "be comfortable". That means that human product interaction needs to be assessed in order to develop suitable products for human use. The first step is to define the user group and understand its variability (see above), in order to employ human test subjects as comprehensive analysis tools. Depending on the respective research question, testing is performed either with lay persons, professional users, expert panels, or with digital human models: For instance, professional users are necessary for the evaluation of specific innovations such as new operation concepts, while expert panels are most valuable for rating comfort related innovation such as new contours or materials. Lay persons can evaluate reach, pressure and vibration related content, and the selection of designs to be tested with human subjects can be defined using digital human models.

For validating innovations, it is sometimes useful to construct special tools for "testing a product without the product". This is especially necessary in cases where product parameters are still being defined and thus a variable tool leads to a quicker answer than a series of prototypes. For instance, testing of seat pivot points, centerlines and contouring becomes possible with a contouring tool that allows for independent settings of these parameters. Reducing discomfort for the user groups is the first step towards successful product development and thus forms the basis of product design. Attaining comfort for all aspects of interaction form further steps towards achieving "perceived quality" and thus product comfort for the final product in use. 


\section{SPECIAL ISSUE: COMFORT}

Eighteen of the papers featured in this special issue of Applied Ergonomics were selected from the presentations of the first Comfort Congress, which was held in Salerno in 2017. For the first time, researchers met at a congress dedicated to product comfort for discussing new perspectives of comfort improvement in human experience in every field of design and engineering. Fifty one papers were presented during the Comfort Congress by researchers and academics coming from more than twenty countries around the world.

The conference was divided into eight thematic sessions about Methodology, Tools, Modeling, Thermal, Psychophysics, Seating, Dynamics and Applications.

A word-count of all papers showed the word "comfort" 1912 times, the word "Discomfort" 679 times, the word "Design" 953 times, the word Human 637 times, the word "Model" 674 times, the word "Seat" 1560 times and the word "Method" 381 times. These keywords show the focus of the Comfort Congress, and represent, the keywords of the majority of the presented papers.

This Special Issue on "Comfort" selected eighteen papers from the Comfort Congress, that have been extended for this purpose, and another four papers on seating comfort that were accepted from the "call for papers" for this Special Issue of Applied Ergonomics.

The selected papers cover a broad scope of the (dis)comfort related topics. Several examples of the aforementioned perception models (Vink, Naddeo) and the cake model (Mansfield) are discussed in several of the papers..

- Three papers (Pandolfi et al., Hirao et al., Mitsuya et al.) present methodologies to assess comfort performance inside the product development process, showing three different methodological approaches able to investigate the "layers" of the cake;

- Four papers (Camps et al, Wang et al., Wegner et al., Raccuglia et al.) focus on tools for "measuring" the comfort through the physical parameters acquired during the interaction between human and artefacts;

- Three papers (Menegon da Silva et al., Diels et al, Califano et al.) consider new proposals to improve the mathematical model of perception shown in (1) (Naddeo et al., 2014);

- Four papers (Scheffelmeier et al., Varela et al., Cappetti et al., Kim et al.) are focused on methodology to investigate the existing link between the psychophysical reaction of the human body and the parameters characterizing the interaction between human and product;

- Finally, eight papers (Smulders et al., Vanacore et al., Kratzenstein et al., Hiemstra van Mastrigt et al, Li et al., Anjani et al., van der Voort et al., Fasulo et al.) examine the application of known and novel methodologies to investigate the seating comfort in different types of seating systems (aircraft seats, car seats, school chairs) or the comfort experience inside a vehicle, showing the direct link between theory, modelling, simulations and application to real-world problems.

We suggest that you make yourself comfortable and enjoy this collection of the state-ofthe-art. 


\section{Literature}

Ahmadpour N, JM Robert, G Lindgaard, 2016. Aircraft passenger comfort experience: Underlying factors and differentiation from discomfort, Applied Ergonomics 52, 301-308.

Bazley C. M. (2015). Beyond comfort in built environments. PhD Delft University of Technology, Delft, doi: 10.4233/uuid: ebb82e2d-e786-4bcf-8c49-b7871932726d.

Bazley, C., Nugent, R., Vink, P. (2015). Patterns of discomfort. Journal of Ergonomics. 5:1. http://dx.doi.org/10.4172/21657556.1000136.

Bazley, C., Vink, P., Montgomery, J., Hedge, A., \& De Jong, A. Work 54 (2016) 791-806. doi: 10.3233/WOR-162347, IOS Press. Interior effects on comfort in healthcare waiting areas. Work: Special Issue on Environmental Design.

Bouwens, J WJ Tsay, P Vink 2018 Ranking of Human Senses in Relation to Different In-flight Activities Contributing to the Comfort Experience of Airplane Passengers. International Journal of Aviation, Aeronautics, and Aerospace 5 (2), article 9 Brauer, K., 2004. Presentation at the aircraft interior EXPO 2004.

Borg G, 1990. Psychophysical scaling with application in physical work and the perception of exertion. Scandinavian Journal of Work, Environment \& Health 16 (Suppl. 1): 55-58.

Bronkhorst RE, Kuijt-Evers LFM, Cremer R, Rhijn JW van, Krause F, Looze MP de, Rebel J. 2001. Emotion and comfort in cabins: report TNO, Hoofddorp, Publ.nr. R2014871/ 402005.

Bronkhorst RE, Krause F. 2005. Designing comfortable passenger seats. In: Vink P, ed. Comfort and Design: Principles and Good Practice. Boca Raton: CRC Press: 155-168.

Capetti N, A Naddeo, R Califano, M Vallone, 2016 Using axiomatic design to identify the elements that affect the evaluation of comfort/discomfort perception. Advances in Social \& Occupational Ergonomics, 235-248.

Ebe, K., Griffin, M. J., 2001. Factors affecting static seat cushion comfort. Ergonomics, 44(10), 901-921.

Franz M, Durt A, Zenk R, Desmet PMA. 2012. Comfort effects of a new car headrest with neck support. Applied Ergonomics 43: 336-343.

Frohriep, S., 2009. Comfort Evaluation in Simulations: Meaningful Use of “Virtual Comfort" Proceedings of Digital Process Management and the Digital Factory, June 16 - 18, 2009, pp. 179 - 184, Magdeburg.

Frohriep, S., 2017. „Funktionsbasierte Nutzfahrzeugentwicklung bei der Grammer AG,“ Proceedings Forum Technische Logistik und Arbeitssysteme 2017, pp 33 - 41, Dresden.

Frohriep, S. 2018. A holistic approach to operator system comfort,” S. Bagnara et al. (Eds.): IEA 2018, AISC 827, pp. 258 - 267

Galinsky TL, Swanson NG, Sauter SL, Hurrell JJ, Schleifer LM, 2000. A field study of supplementary rest breaks for data-entry operators. Ergonomics 43(5): 622-638.

Grinten MP van der, Smitt P. 1992. Development of a practical method for measuring body part discomfort. In: Kumar, S. (Ed.), Advances in Industrial Ergonomics and Safety IV. Taylor \& Francis, London, 311-318.

Groenesteijn, L, 2015, seat design in the context of knowledge work, PhD thesis, TU-Delft.

Groenesteijn L, Ellegast RP, Keller K, Krause F, Berger H, De Looze MP. 2012. Office task effects on comfort and body dynamics in five dynamic office chairs. Applied Ergonomics 43(2): 320-328.

Groenesteijn L, Hiemstra-van Mastrigt S, Gallais C, Blok MM, Kuijt-Evers, LFM, 2014. M, Vink P. Activities, postures and comfort perception of train passengers as input for train seat design. Ergonomics 57(8): 1154- 1165.

Hamberg-van Reenen, H.H., A.J. van der Beek, B.M. Blatter M.P. van der Grinten, W. van, Mechelen, P.M. Bongers, 2008. Does musculoskeletal discomfort at work predict future musculoskeletal pain? Ergonomics 51: 637-648.

Hekkert P, Schifferstein HNJ (eds), 2007. Product experience. Elsevier Science \& Technology, Amsterdam.

Helander MG, Zhang L. 1997. Field studies of comfort and discomfort in sitting. Ergonomics 40; 895-915.

Hiemstra-van Mastrigt, S., 2015. Comfortable passenger seats. Recommendations for design and research. PhD thesis, TU-Delft. Hiemstra-van Mastrigt S, L Groenesteijn, P Vink, LFM Kuijt-Evers, 2017. Predicting passenger seat comfort and discomfort on the basis of human, context and seat characteristics: a literature review, Ergonomics 60 (7), 889-911.

Hofmann A., 2018. From outside-in towards inside-out. Is it a paradigm shift necessary in automobile design? PhD thesis, TUDelft, Delft.

Kolich M. 1999. Reliability and Validity of an Automobile Seat Comfort Survey, Technical, SAE Technical Paper 1-13.

Kolich M, 2018. Lincoln Continental's Perfect Position Seat, presentation at $3^{\text {rd }}$ Annual Automotive Seating Summit, Munich.

Kuijt-Evers LFM, Groenesteijn L, Looze MP de, Vink P. Identifying factors of comfort in using hand tools. Applied Ergonomics $2004 ; 35(5): 453-458$.

Kuijt-Evers LFM, T Bosch, MA Huysmans, MP De Looze, P Vink, 2007, Association between objective and subjective measurements of comfort and discomfort in hand tools Applied ergonomics 38 (5), 643-654.

Looze, M. P. de, Kuijt-Evers, L. F. M., Dieën, J. van, 2003. Sitting comfort and discomfort and the relationships with objective measures. Ergonomics, 46(10), 985-997. doi: 10.1080/0014013031000121977.

Mansfield, N.J., 2005.Human Response to Vibration, CRC Press, London, UK, 2005.Mansfield, N.J., Mackrill, J., Rimell, A.N. and MacMull, S.J., 2014. Combined effects of long-term sitting and whole-body vibration on discomfort onset for vehicle occupants. ISRN automotive engineering, 2014.

Mergl C, Klendauer M, Mangen C, Bubb H, 2005. Predicting long term riding comfort in cars by contact forces between human and seat. SAE, Warrendale. Technical Paper No. 2005-01-2690.

Moes NCCM. 2005. Analysis of sitting discomfort, a review. In: Bust, PD, McCabe, PT (Eds.), Contemporary Ergonomics. Taylor \& Francis, London, pp. 200-204.

Mokdad M, Al-Ansari M 2009, Anthropometrics for the design of Bahraini school furniture. International Journal of Industrial Ergonomics 39(5): 728-735.

Naddeo A, S Memoli, 2009. Postural Comfort Inside a Car: Development of an innovative model to evaluate the discomfort level. SAE International Journal of Passenger Cars - Mechanical Systems 2 (2009-01).

Naddeo A, N Cappetti, R Califano, M Vallone, (2015), The role of expectation in comfort perception: the mattresses' evaluation experience Procedia Manufacturing 3, 4784-4791. 
Naddeo, A., Cappetti, N., D'Oria, C., 2015. Proposal of a new quantitative method for postural comfort evaluation. International Journal of Industrial Ergonomics, 48, 25-35. doi:10.1016/j.ergon.2015.03.008.

Naddeo, A., Cappetti, N., Vallone, M., Califano, R., 2014. New trend line of re-search about comfort evaluation: proposal of a framework for weighing and evaluating contributes coming from cognitive, postural and physiologic comfort perceptions. In T. Ahram, W. Karwowski, \& T. Marek (Eds.), AHFE 2014, Krakow, Poland, 19-23 July 2014.

Naddeo, A., Califano, R., Cappetti, N., Vallone, M. (2016). The effect of external and environmental factors on perceived comfort: the car-seat experience, In D. de Waard, K.A. Brookhuis, A. Toffetti, A. Stuiver, C. Weikert, D. Coelho, D. Manzey, A.B. Ünal, S. Röttger, and N. Merat (Eds.). Proceedings of the Human Factors and Ergonomics Society Europe Chapter 2015 Annual Conference (pp. 291-308).

Naddeo A., 2017. Towards predicting the (dis)comfort performance by modelling: methods and findings, PhD dissertation, TU Delft (NL) Institutional Repository, doi: 10.4233/uuid: ac8ebee1-278c-484d-acc0-d39c765c1ac2, ISBN: 978-94-6186-870-1.

Pheasant, S. and Haslegrave, C.M. (2006) Bodyspace: Anthropometry, Ergonomics, and the Design of Work. CRC Press, Boca Raton.

Sammonds, G.M., Fray, M. and Mansfield, N.J., 2017. Effect of long term driving on driver discomfort and its relationship with seat fidgets and movements (SFMs). Applied Ergonomics, 58, pp.119-127.

Shen W, Parsons KC, 1997. Validity and reliability of rating scales for seated pressure discomfort. International Journal of Industrial Ergonomics 20: 249-461.

Smulders M, Berghman K, Koenraads M, Kane JA, Krishna K, Carter TK, 2016, Comfort and pressure distribution in a human contour shaped aircraft seat (developed with 3d scans of the human body). Work. 2016; 54(4): 925-940.

Uhlemann, T.H., Lehmann, C., Steinhilper, R., 2017. The Digital Twin: Realizing the cyber-physical production system for industry 4.0. Procedia CIRP 61: 335-340.

Veen, SAT van, 2016, DRIVER VITALIZATION, Investigating sensory stimulation to achieve a positive driving experience. PhD thesis, TU-Delft.

Vink, P. (ed), 2005, Comfort and Design: Principles and Good Practice, Boca Raton: CRC Press.

Vink, P., Hallbeck, S., 2012. Editorial: Comfort and discomfort studies demonstrate the need for a new model. Applied Ergonomics, 43(2), 271-276. doi:10.1016/j.apergo.2011.06.001.

Vink P, 2014, the sweetness of discomfort. TU-Delft, Delft, the Netherlands.

Vink, P 2017, Vehicle seat comfort and design, Pumbo press, Alkmaar.

Winner, H., Hakuli, S. and G. Wolf (eds.), 2014. Handbuch Fahrerassistenzsysteme. Vieweg+Teubner, Wiesbaden. 